\title{
Efficacy and Safety of Imatinib Mesylate in Advanced Gastrointestinal Stromal Tumors
}

\section{Citation}

Demetri, George D., Margaret von Mehren, Charles D. Blanke, Annick D. Van den Abbeele, Burton Eisenberg, Peter J. Roberts, Michael C. Heinrich, et al. 2002. "Efficacy and Safety of Imatinib Mesylate in Advanced Gastrointestinal Stromal Tumors." New England Journal of Medicine 347 (7) (August 15): 472-480. doi:10.1056/nejmoa020461.

\section{Published Version}

10.1056/nejmoa020461

\section{Permanent link}

http://nrs.harvard.edu/urn-3:HUL.InstRepos:33953714

\section{Terms of Use}

This article was downloaded from Harvard University's DASH repository, and is made available under the terms and conditions applicable to Other Posted Material, as set forth at http:// nrs.harvard.edu/urn-3:HUL.InstRepos:dash.current.terms-of-use\#LAA

\section{Share Your Story}

The Harvard community has made this article openly available.

Please share how this access benefits you. Submit a story.

\section{Accessibility}




\title{
EFFICACY AND SAFETY OF IMATINIB MESYLATE IN ADVANCED GASTROINTESTINAL STROMAL TUMORS
}

\author{
George D. Demetri, M.D., Margaret von Mehren, M.D., Charles D. Blanke, M.D., \\ Annick D. Van den Abbeele, M.D., Burton Eisenberg, M.D., Peter J. Roberts, M.D., Michael C. Heinrich, M.D., \\ David A. Tuveson, M.D., Ph.D., Samuel Singer, M.D., Milos Janicek, M.D., Ph.D., Jonathan A. Fletcher, M.D., \\ Stuart G. Silverman, M.D., Sandra L. Silberman, M.D., Ph.D., Renaud Capdeville, M.D., Beate Kiese, M.Sc., \\ Bin Peng, M.D., Ph.D., Sasa Dimitrijevic, Ph.D., Brian J. Druker, M.D., Christopher Corless, M.D., \\ Christopher D.M. Fletcher, M.D., AND HeIKKI Joensuu, M.D.
}

\begin{abstract}
Background Constitutive activation of KIT receptor tyrosine kinase is critical in the pathogenesis of gastrointestinal stromal tumors. Imatinib mesylate, a selective tyrosine kinase inhibitor, has been shown in preclinical models and preliminary clinical studies to have activity against such tumors.

Methods We conducted an open-label, randomized, multicenter trial to evaluate the activity of imatinib in patients with advanced gastrointestinal stromal tumor. We assessed antitumor response and the safety and tolerability of the drug. Pharmacokinetics were assessed in a subgroup of patients.

Results A total of 147 patients were randomly assigned to receive $400 \mathrm{mg}$ or $600 \mathrm{mg}$ of imatinib daily. Overall, 79 patients (53.7 percent) had a partial response, 41 patients (27.9 percent) had stable disease, and for technical reasons, response could not be evaluated in 7 patients (4.8 percent). No patient had a complete response to the treatment. The median duration of response had not been reached after a median follow-up of 24 weeks after the onset of response. Early resistance to imatinib was noted in 20 patients (13.6 percent). Therapy was well tolerated, although mildto-moderate edema, diarrhea, and fatigue were common. Gastrointestinal or intraabdominal hemorrhage occurred in approximately 5 percent of patients. There were no significant differences in toxic effects or response between the two doses. Imatinib was well absorbed, with pharmacokinetics similar to those reported in patients with chronic myeloid leukemia.

Conclusions Imatinib induced a sustained objective response in more than half of patients with an advanced unresectable or metastatic gastrointestinal stromal tumor. Inhibition of the KIT signal-transduction pathway is a promising treatment for advanced gastrointestinal stromal tumors, which resist conventional chemotherapy. (N Engl J Med 2002;347:472-80.) Copyright $\odot 2002$ Massachusetts Medical Society.
\end{abstract}

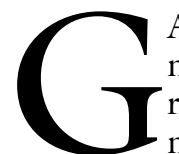
ASTROINTESTINAL stromal tumors are mesenchymal neoplasms that appear to be related to the interstitial cells of Cajal of the myenteric plexus, with which they share certain differentiation markers.1,2 Gastrointestinal stromal tumors express the cell-surface transmembrane receptor KIT that has tyrosine kinase activity and is the protein product of the KIT proto-oncogene. There are frequent gain-of-function mutations of KIT in gastrointestinal stromal tumors. 3,4 These mutations result in the constitutive activation of KIT signaling, which leads to uncontrolled cell proliferation and resistance to apoptosis. It has recently been reported that KIT activation occurs in all cases of gastrointestinal stromal tumor, regardless of the mutational status of KIT.4

Unresectable or metastatic gastrointestinal stromal tumor is a fatal disease that resists conventional cytotoxic chemotherapy. ${ }^{5,6}$ In a recently reported series, the response rate to doxorubicin was less than 5 percent. ${ }^{6}$ The effectiveness of radiation therapy for this disease has not been proved. ${ }^{5}$ The median duration of survival for patients with a metastatic gastrointestinal stromal tumor is approximately 20 months, and for patients with local recurrence it is 9 to 12 months. ${ }^{5}$

Imatinib mesylate (formerly STI571, now referred to as Gleevec in the United States and Glivec in Europe [Novartis]) is a selective inhibitor of certain protein tyrosine kinases: the intracellular ABL kinase, the chimeric BCR-ABL fusion oncoprotein of chronic myeloid leukemia, the transmembrane receptor KIT, and the platelet-derived growth factor receptors. ${ }^{7-10}$ Imatinib is highly active in patients with chronic myeloid leukemia and other Philadelphia chromosome-pos-

\footnotetext{
From the Dana-Farber Cancer Institute and Harvard Cancer Center, Boston (G.D.D., A.D.V.A., D.A.T., S.S., M.J., J.A.F., S.G.S., C.D.M.F.); the Fox Chase Cancer Center, Philadelphia (M.M., B.E.); the Oregon Health and Science University and Portland Veterans Affairs Medical Center, Portland (C.D.B., M.C.H., B.J.D., C.C.); the University of Turku, Turku, Finland (P.J.R.); Novartis Oncology, Basel, Switzerland (S.L.S., R.C., B.K., B.P., S.D.); and the University of Helsinki, Helsinki, Finland (H.J.). Address reprint requests to Dr. Demetri at the Center for Sarcoma and Bone Oncology, Dana-Farber Cancer Institute, SW 530, 44 Binney St., Boston, MA 02115 , or at gdemetri@partners.org.

Drs. Demetri, von Mehren, Blanke, and Joensuu contributed equally to the article.
} 
itive leukemias, in which it inhibits the dysregulated kinase activity of the BCR-ABL fusion protein. ${ }^{11,12} \mathrm{We}$ hypothesized that imatinib might also block the constitutive activity of KIT receptor tyrosine kinase in the cells of gastrointestinal stromal tumors. This hypothesis was supported by experiments in human tumorcell lines that are dependent on the KIT pathway. Exposure of these cells to imatinib blocked the kinase activity of KIT, arrested proliferation, and caused apoptotic cell death. ${ }^{9,10,13}$ Subsequently, a single patient treated with imatinib for a chemotherapy-resistant metastatic gastrointestinal stromal tumor had a rapid, substantial, and durable response. ${ }^{14}$ To build on these results, we conducted a multicenter clinical trial to test the efficacy and safety of imatinib in patients with an unresectable or metastatic gastrointestinal stromal tumor.

\section{METHODS}

\section{Patients}

Adults with a histologically confirmed, unresectable or metastatic gastrointestinal stromal tumor that expressed CDl17 (a marker of KIT-receptor tyrosine kinase) were eligible for the study. Pathology was reviewed centrally by a single pathologist. Criteria for inclusion were at least one measurable tumor that had not previously been treated with radiotherapy or embolization; adequate hepatic, renal, and cardiac function; an adequate platelet count; and an Eastern Cooperative Oncology Group (ECOG) performance status of 3 or lower. Patients were allowed to have received any number of previous chemotherapeutic regimens (with the last administration of chemotherapy at least four weeks before study entry) and to have undergone radiotherapy, surgery, or both. The study was approved by the institutional review board of each participating institution, and written informed consent was obtained from all patients.

\section{Study Design}

We conducted a randomized, open-label, multicenter trial designed to evaluate the activity of imatinib in inducing objective responses in gastrointestinal stromal tumors. Randomization was performed centrally without stratification according to site or any other factor. Blocking, with a block size of four, was used. Secondary objectives were the assessment of pharmacokinetics, safety, time to treatment failure, and survival. Standard $\left[{ }^{18} \mathrm{~F}\right]$ fluoro-2-deoxy-D-glucose positron-emission tomographic (PET) scanning was performed in 64 patients to complement standard computed tomographic (CT) imaging and assess changes in the metabolic profiles of the tumors. Histopathological and molecular changes during treatment were evaluated in selected patients by means of serial biopsies of the tumor.

Patients were randomly assigned to receive either $400 \mathrm{mg}$ or $600 \mathrm{mg}$ of imatinib orally, taken once daily with food, in the form of 100-mg capsules. These doses were chosen on the basis of data from patients with chronic myeloid leukemia ${ }^{11}$ in order to achieve target plasma concentrations that could be expected to inhibit KIT activity. 9,13 Patients receiving $400 \mathrm{mg}$ per day whose tumor progressed but who were otherwise in good clinical condition were eligible to increase the dose to $600 \mathrm{mg}$ per day. Patients whose tumor progressed despite treatment with $600 \mathrm{mg}$ per day were withdrawn from the study.

Patients had regular physical examinations and evaluations of performance status, body weight, complete blood count, and serum chemistry. The administration of each dose and any adverse events were recorded in a diary for each patient.
The study was designed by the academic investigators in collaboration with Novartis. The academic investigators and their respective teams at the four centers collected and managed all of the data. The data were then collected in a central data base and made fully available to the principal investigators at each study site. The team met regularly and had twice-monthly conference calls to discuss study progress and results. The overall results were analyzed by the principal investigators and employees of Novartis. This article was written by Dr. Demetri with substantive collaboration from the principal investigators and all other authors.

\section{Efficacy and Safety Evaluation}

The response of the tumor to imatinib was evaluated after one month, three months, and six months, and every six months thereafter or whenever there was a medical need. Assessments were according to the standard Southwest Oncology Group criteria and were based solely on CT or magnetic resonance imaging (MRI). ${ }^{15}$ Responses were classified as complete responses (disappearance of all disease that could be measured and evaluated); partial responses $(\geqslant 50$ percent decrease in the sum of the products of the perpendicular diameters of all measurable lesions, the absence of progression, and the absence of new lesions); stable disease (a response that did not qualify as a complete response, a partial response, or disease progression); or disease progression ( $\geqslant 50$ percent increase or an increase of $10 \mathrm{~cm}^{2}$ [whichever was smaller] in the sum of the products of the perpendicular diameters of all measurable lesions, worsening of a lesion that could be evaluated, the reappearance of any lesion or the presence of a new lesion, or failure of the patient to return for evaluation because of disease progression). All responses had to be confirmed by repeated imaging within 4 to 12 weeks. Time to treatment failure was defined as the time from the first dose of imatinib to the earliest occurrence of progression, death from any cause, or withdrawal from the trial for any reason other than that the condition no longer required therapy. Data for patients who had not had disease progression or died or who were withdrawn from the trial for any reason other than that their condition no longer required therapy were censored at the time of the last assessment of the tumor. Toxic effects were graded according to the National Cancer Institute Common Toxicity Criteria. ${ }^{16}$

Immunohistochemical analysis for the detection of CD117 was performed with the use of polyclonal rabbit antiserum (A4502, Dako) and routine methods for immunohistochemical analysis without any antigen retrieval. ${ }^{17}$ Biopsy specimens of the tumor were obtained from selected consenting patients before and after treatment for the histopathological assessment of treatment, mutational analyses of KIT, and immunoblotting for detection of KIT phosphoprotein. ${ }^{4}$

\section{Pharmacokinetics}

Plasma samples were collected from a subgroup of patients before treatment and then $1,2,3,8,24,48$, and 72 hours after the administration of the drug. Sampling at the same intervals was repeated after four weeks of treatment. The plasma imatinib concentration was determined by liquid chromatography and mass spectrometry as previously reported..$^{18}$

\section{Statistical Analysis}

The original sample size was based on a proof-of-concept approach, according to which we required at least 3 patients with a response among 18 treated patients in each group in order to continue enrolling patients in the study. This rule resulted in a 94 percent probability of rejection of the null hypothesis if either dose level had a true response rate of less than 5 percent and a probability of rejection of the null hypothesis of less than 6 percent if either dose level had a true response rate of 30 percent or greater. Because of the promising results observed, the study was enlarged to allow recruitment of up to 200 patients; 147 patients were recruited. With 
an intention-to-treat population of 147 patients, the 95 percent confidence interval for response rate was no wider than \pm 8.4 percent. Such a confidence interval was judged sufficient to allow a meaningful comparison with historical data.

After the first 100 patients completed the six-month assessment, an interim analysis was performed, and the evidence of efficacy and safety was judged sufficient for submission to health authorities for registration of the drug. This report provides updated results. All reported $\mathrm{P}$ values are two-sided.

\section{RESULTS}

\section{Patients}

Between July 2000 and April 2001, 147 patients were recruited at four study centers. Characteristics of the patients are summarized in Table 1 . The diagnosis of CD117-positive gastrointestinal stromal tumor was confirmed by central review in 135 of 137 cases (98.5 percent); 2 patients were judged to be ineligible because of the absence of CD117 expression in the proper histopathological context, ${ }^{19}$ and in 10 cases, patho-

Table 1. Characteristics of the Patients.

\begin{tabular}{|c|c|}
\hline Characteristic & $\begin{array}{l}\text { ALL PATIENTS } \\
\text { (N=147) }\end{array}$ \\
\hline \multicolumn{2}{|l|}{ Age $-\mathrm{yr}$} \\
\hline Median & 54 \\
\hline Range & $18-83$ \\
\hline \multicolumn{2}{|l|}{ Sex - no. (\%) } \\
\hline Male & $83(56.5)$ \\
\hline Female & $64(43.5)$ \\
\hline \multicolumn{2}{|l|}{ ECOG status - no. $(\%)^{*}$} \\
\hline Grade 0 & $62(42.2)$ \\
\hline Grade 1 & $57(38.8)$ \\
\hline Grade 2 & $27(18.4)$ \\
\hline Grade 3 & $1(0.7)$ \\
\hline \multicolumn{2}{|c|}{ Site of tumor at diagnosis - no. $(\%) \dagger$} \\
\hline Small intestine & $72(49.0)$ \\
\hline Stomach & $50(34.0)$ \\
\hline Liver & $25(17.0)$ \\
\hline Peritoneum & $19(12.9)$ \\
\hline Omentum & 17 (11.6) \\
\hline \multicolumn{2}{|c|}{ Site of tumor at recurrence - no. $(\%)$} \\
\hline Any recurrent diseasef & $132(89.8)$ \\
\hline Liver & $115(78.2)$ \\
\hline Peritoneum & $56(38.1)$ \\
\hline Retroperitoneum & $21(14.3)$ \\
\hline \multicolumn{2}{|c|}{ Previous treatment - no. $(\%)$} \\
\hline Surgery & $144(98.0)$ \\
\hline Chemotherapy & $75(51.0)$ \\
\hline Radiotherapy & $22(15.0)$ \\
\hline
\end{tabular}

*Eastern Cooperative Oncology Group (ECOG) status is graded on a scale from 0 to 5 , with 0 denoting fully active and 5 death. A score of 3 indicates that the patient is capable of limited self-care but is confined to a bed or chair more than 50 percent of his or her waking hours.

†Some patients had tumors at more than one site; patients with tumors in the liver had metastatic disease at initial presentation.

$\ddagger$ Some patients had recurrent disease at more than one site. logic material was unavailable for central review. The analyses presented here include data from all $147 \mathrm{pa}-$ tients on an intention-to-treat basis.

Previous therapy included surgery in 144 patients (98.0 percent), chemotherapy for metastatic or unresectable disease in 75 patients ( 51.0 percent), and radiotherapy in 22 patients ( 15.0 percent). Patients who had previously undergone chemotherapy had received between one and seven regimens (median, two). None of them had exhibited an objective response to any previous regimen. Patients generally had far-advanced, bulky disease, and the mean total area of tumors was $173 \mathrm{~cm}^{2}$ (range, 1 to 1130 ).

\section{Pharmacokinetics}

Imatinib was detectable in plasma soon after oral administration of either a $400-\mathrm{mg}$ dose or a $600-\mathrm{mg}$ dose, with a mean half-life in the circulation of approximately 20 hours. The mean plasma concentration increased with increases in the dose, with variability between patients similar to that described in patients with chronic myeloid leukemia. ${ }^{20}$ The mean $( \pm$ SE) area under the curve after four weeks of treatment was $6 \mathrm{l} \pm 25 \mu \mathrm{g}$-hr per milliliter for the $400-\mathrm{mg}$ dose and $75 \pm 31 \mu \mathrm{g}$-hr per milliliter for the 600-mg dose.

\section{Antitumor Response}

With follow-up of more than 9 months for all patients (the median follow-up was 288 days as of October 15, 2001, the last date of data collection for this report), 120 patients (81.6 percent) remained in the study. Data on antitumor response are shown in Table 2. No patient had a complete response. Overall, 53.7 percent of the patients had a partial response. All these partial responses were confirmed by repeated imaging at least 28 days later. The reduction in the bulk of the tumor among patients who had a partial response ranged from 50 percent to 96 percent. An additional 27.9 percent of patients had stable disease, and disease progression was noted in 13.6 percent of patients between one and three months after study entry. The median time to an objective response was 13 weeks. Responses have been durable for more than 46 weeks and the median duration of response has not been reached as of this writing (median follow-up, 24 weeks after the onset of response). There were no significant differences in the rate or duration of response between the dose levels of imatinib mesylate we tested.

The time to treatment failure and overall survival are shown in Figure 1. Of nine patients who were assigned to receive the lower dose and who were later given the higher dose because of disease progression, one subsequently had a partial response, and two had stable disease after the crossover to $600 \mathrm{mg}$ per day. Nine patients treated with $400 \mathrm{mg}$ per day and five

474 • N Engl J Med, Vol. 347, No. 7 • August 15, $2002 \cdot$ www.nejm.org 
Table 2. Responses to Imatinib in Patients with Advanced Gastrointestinal STROMAL Tumors.*

\begin{tabular}{|c|c|c|c|}
\hline \multirow[t]{2}{*}{ BESt RESPONSE } & $\begin{array}{l}400 \mathrm{mg} \\
(\mathrm{N}=73)\end{array}$ & $\begin{array}{l}600 \mathrm{mg} \\
(\mathrm{N}=74)\end{array}$ & $\begin{array}{l}\text { EITHER DOSE } \\
(\mathbf{N}=147)\end{array}$ \\
\hline & & no. $(\%[95 \% \mathrm{CI}])$ & \\
\hline Complete response & 0 & 0 & 0 \\
\hline Partial response & $36(49.3[37.4-61.3])$ & $43(58.1[46.1-69.5])$ & $79(53.7[45.3-62.0])$ \\
\hline Stable disease & $23(31.5[21.1-43.4])$ & $18(24.3[15.1-35.7])$ & $41(27.9[20.8-35.9])$ \\
\hline Progressive disease & $12(16.4)$ & $8(10.8)$ & $20(13.6)$ \\
\hline Could not be evaluated & $2(2.7)$ & $5(6.8)$ & $7(4.8)$ \\
\hline
\end{tabular}

${ }^{*} \mathrm{CI}$ denotes confidence interval.

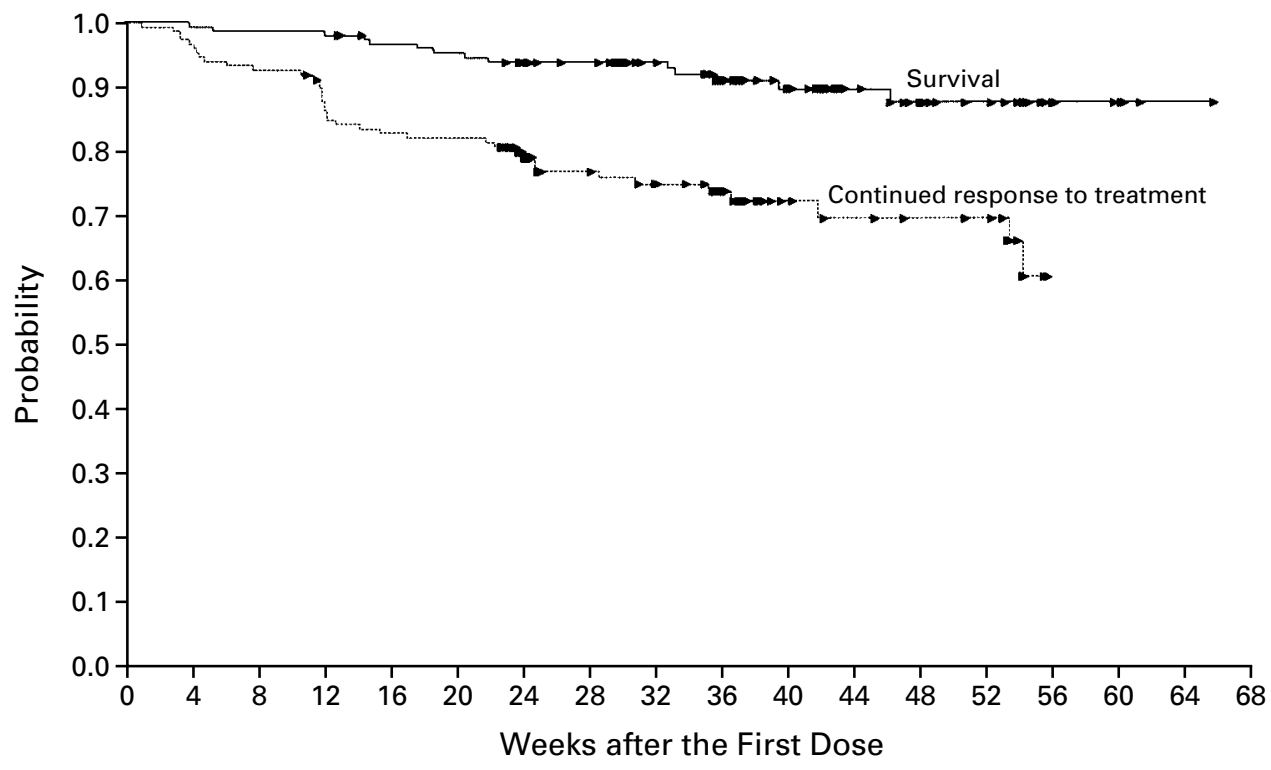

Figure 1. Kaplan-Meier Estimates of Overall Survival and Time to Treatment Failure for All Patients. Each arrowhead represents the point at which a patient's data were censored.

patients treated with $600 \mathrm{mg}$ per day died. Five patients in the 400-mg group and eight patients in the $600-\mathrm{mg}$ group were withdrawn from the study. Disease progression during treatment occurred in 11 patients receiving $600 \mathrm{mg}$ per day and 8 patients receiving $400 \mathrm{mg}$ per day. The estimated one-year survival rate for all patients was 88 percent. Median survival has not been reached as of this writing.

Standard [18F]fluoro-2-deoxy-D-glucose PET proved to be a sensitive, rapid, and reliable indicator of response or resistance to imatinib. In all patients with a response, the $\left[{ }^{18} \mathrm{~F}\right]$ fluoro-2-deoxy-D-glucose up- take in the tumor had decreased markedly from base line as early as 24 hours after a single dose of imatinib. Increases in tumor-related glycolytic activity, activity at new sites, or both were seen in all patients with disease progression. PET results correlated with subsequent evidence of a response or progression on CT or MRI. PET and CT scans from a representative patient with a response are shown in Figure 2.

Performance status improved with imatinib treatment. By month 4 of the study, with 144 patients still receiving treatment, the number of patients with normal functional status (an ECOG performance status 

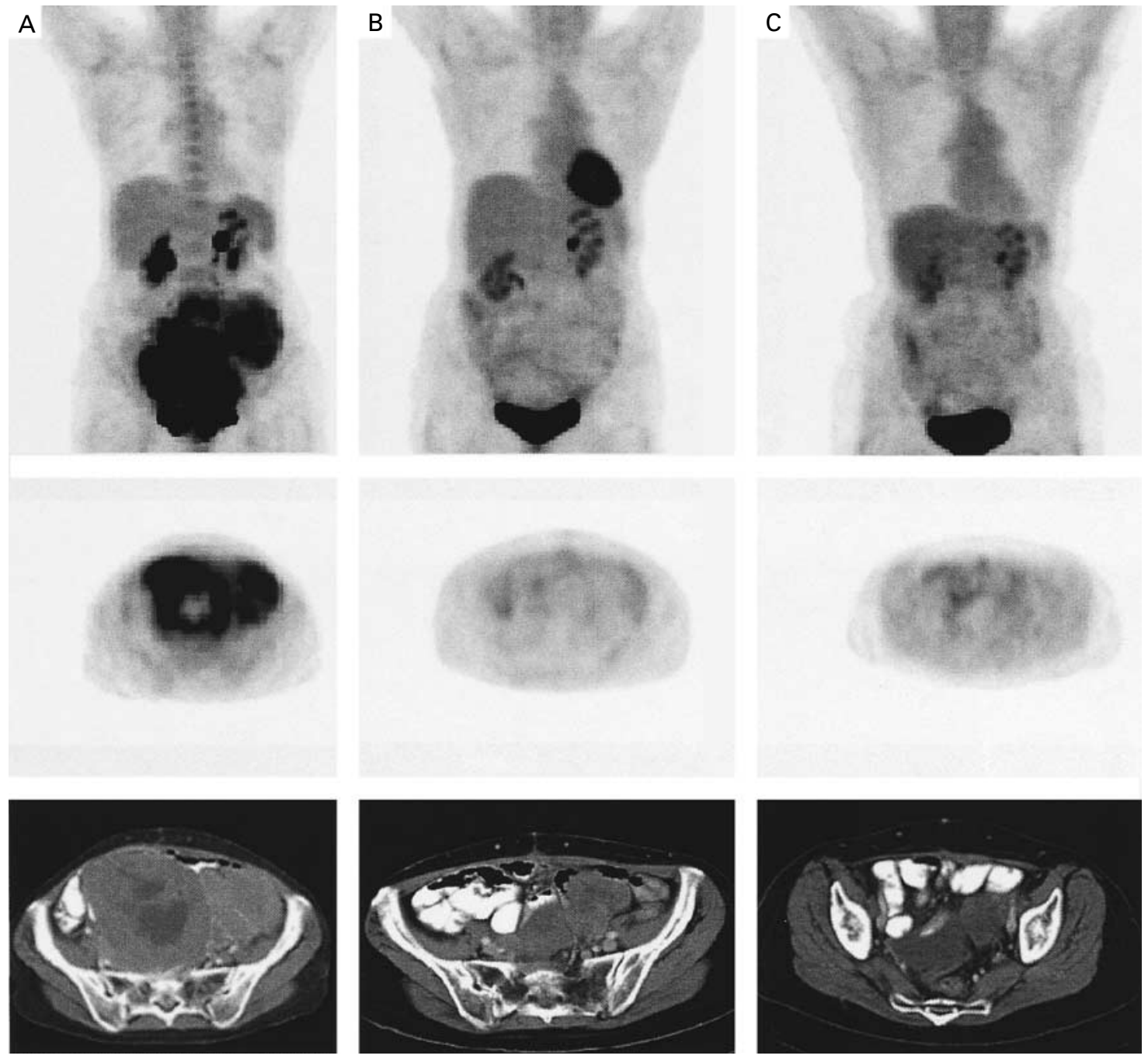

Figure 2. Sequential PET Scans Obtained in the Same Patient at Base Line (before Treatment, Panel A), 1 Month after Imatinib Treatment Began (Panel B), and after 16 Months of Continuous Treatment (Panel C).

The images at each point include a two-dimensional PET scan of the body (top), an axial PET scan of a slice through the site of the pelvic tumor (middle), and a correlating CT scan at the corresponding level. The standardized uptake values for the tumor at the three time points were 4.5 (Panel A), 1.24 (Panel B), and 0.75 (Panel C). The uptake in the cardiac blood pool, the myocardium, the liver, the bowel, the bilateral renal collecting system, and the bladder is within physiologic limits in this patient. Images were obtained with the use of similar doses of [18F]fluoro-2-deoxy-D-glucose, acquisition times, and protocols at the three time points. The patient also had similar blood glucose concentrations at each of these three time points.

of 0 ) had increased to 64 percent from 42 percent at study entry. Similarly, by month 4 , the number of patients with substantially impaired functional status (a performance status of 2 to 3 ) had decreased to 5 percent from 19 percent at entry.

\section{Safety}

Treatment with imatinib was generally well tolerated, although virtually every patient had at least some mild or moderate adverse events (grade 1 or 2 ) that might have been related to therapy. The most common adverse events included edema (in 74.1 percent of patients) that was most frequently periorbital, nausea (in 52.4 percent), diarrhea (in 44.9 percent), myalgia or musculoskeletal pain (in 39.5 percent), fatigue (in 34.7 percent), dermatitis or rash (in 30.6 percent), headache (in 25.9 percent), and abdominal pain (in 25.9 percent) (Table 3 ). Most of these adverse events were mild or moderate. There was no hyperuricemia or evidence of tumor lysis syndrome, even in patients 
Table 3. Adverse Effects with a Possible or Suspected Relation to Imatinib.*

\begin{tabular}{|c|c|c|c|c|c|c|}
\hline \multirow[t]{2}{*}{ AdVERSE EFFECT } & \multicolumn{3}{|c|}{ Any Grade } & \multicolumn{3}{|c|}{ Grade 3 or 4} \\
\hline & $\begin{array}{l}400 \mathrm{mg} \\
(\mathrm{N}=73)\end{array}$ & $\begin{array}{l}600 \mathrm{mg} \\
(\mathrm{N}=74)\end{array}$ & $\begin{array}{l}\text { ALL PATIENTS } \\
\quad(\mathrm{N}=147)\end{array}$ & $\begin{array}{l}400 \mathrm{mg} \\
(\mathrm{N}=73)\end{array}$ & $\begin{array}{l}600 \mathrm{mg} \\
(\mathrm{N}=74)\end{array}$ & $\begin{array}{l}\text { ALL PATIENTS } \\
(\mathrm{N}=147)\end{array}$ \\
\hline & \multicolumn{6}{|c|}{ number (percent) } \\
\hline $\begin{array}{l}\text { Any adverse effect with suspected relation } \\
\text { to study drug }\end{array}$ & $71(97.3)$ & $73(98.6)$ & $144(98.0)$ & $15(20.5)$ & $16(21.6)$ & $31(21.1)$ \\
\hline $\begin{array}{l}\text { Edema or fluid retention } \\
\text { Periorbital } \\
\text { Leg } \\
\text { Face } \\
\text { Other site } \\
\text { Eyelid }\end{array}$ & $\begin{aligned} 52 & (71.2) \\
33 & (45.2) \\
19 & (26.0) \\
6 & (8.2) \\
5 & (6.8) \\
5 & (6.8)\end{aligned}$ & $\begin{aligned} 57 & (77.0) \\
37 & (50.0) \\
11 & (14.9) \\
9 & (12.2) \\
10 & (13.5) \\
6 & (8.1)\end{aligned}$ & $\begin{array}{r}109(74.1) \\
70(47.6) \\
30(20.4) \\
15(10.2) \\
15(10.2) \\
11(7.5)\end{array}$ & $\begin{array}{l}1(1.4) \\
0 \\
0 \\
1(1.4) \\
0 \\
0\end{array}$ & $\begin{array}{l}1(1.4) \\
0 \\
0 \\
0 \\
0 \\
0\end{array}$ & $\begin{array}{l}2(1.4) \\
0 \\
0 \\
1(0.7) \\
0 \\
0\end{array}$ \\
\hline Nausea & $37(50.7)$ & $40(54.1)$ & $77(52.4)$ & $1(1.4)$ & $1(1.4)$ & $2(1.4)$ \\
\hline Diarrhea & $29(39.7)$ & $37(50.0)$ & $66(44.9)$ & $1(1.4)$ & $2(2.7)$ & $3(2.0)$ \\
\hline Myalgia or musculoskeletal pain & $27(37.0)$ & $31(41.9)$ & $58(39.5)$ & 0 & 0 & 0 \\
\hline Fatigue & $22(30.1)$ & $29(39.2)$ & $51(34.7)$ & 0 & 0 & 0 \\
\hline Dermatitis or rash & $18(24.7)$ & $27(36.5)$ & $45(30.6)$ & $2(2.7)$ & $2(2.7)$ & $4(2.7)$ \\
\hline Headache & $14(19.2)$ & $24(32.4)$ & $38(25.9)$ & 0 & 0 & 0 \\
\hline Abdominal pain & $19(26.0)$ & $19(25.7)$ & $38(25.9)$ & $1(1.4)$ & 0 & $1(0.7)$ \\
\hline Flatulence & $14(19.2)$ & $18(24.3)$ & $32(21.8)$ & 0 & 0 & 0 \\
\hline Vomiting & $10(13.7)$ & $9(12.2)$ & $19(12.9)$ & 0 & $1(1.4)$ & $1(0.7)$ \\
\hline $\begin{array}{l}\text { Hemorrhage } \\
\text { Tumor hemorrhage } \\
\text { Cerebral hemorrhage or subdural hematoma } \\
\text { Upper GI tract bleeding or perforation }\end{array}$ & $\begin{array}{l}8(11.0) \\
1(1.4) \\
0 \\
3(4.1)\end{array}$ & $\begin{array}{l}10(13.5) \\
3(4.1) \\
0 \\
2(2.7)\end{array}$ & $\begin{array}{l}18(12.2) \\
4(2.7) \\
0 \\
5(3.4)\end{array}$ & $\begin{array}{l}3(4.1) \\
1(1.4) \\
0 \\
3(4.1)\end{array}$ & $\begin{array}{l}4(5.4) \\
3(4.1) \\
0 \\
1(1.4)\end{array}$ & $\begin{array}{l}7(4.8) \\
4(2.7) \\
0 \\
4(2.7)\end{array}$ \\
\hline Dyspepsia & $7(9.6)$ & $9(12.2)$ & $16(10.9)$ & 0 & 0 & 0 \\
\hline Increased lacrimation & $5(6.8)$ & $9(12.2)$ & $14(9.5)$ & 0 & 0 & 0 \\
\hline Anemia & $4(5.5)$ & $9(12.2)$ & $13(8.8)$ & $1(1.4)$ & $2(2.7)$ & $3(2.0)$ \\
\hline Loose stools & $5(6.8)$ & $7(9.5)$ & $12(8.2)$ & 0 & 0 & 0 \\
\hline Taste disturbance & $2(2.7)$ & $10(13.5)$ & $12(8.2)$ & 0 & 0 & 0 \\
\hline Neutropenia & $6(8.2)$ & $4(5.4)$ & $10(6.8)$ & $5(6.8)$ & $2(2.7)$ & $7(4.8)$ \\
\hline Abdominal distention & $4(5.5)$ & $4(5.4)$ & $8(5.4)$ & 0 & 0 & 0 \\
\hline Abnormal liver-function results & $4(5.5)$ & $4(5.4)$ & $8(5.4)$ & $2(2.7)$ & $2(2.7)$ & $4(2.7)$ \\
\hline Leukopenia & $4(5.5)$ & $3(4.1)$ & $7(4.8)$ & $2(2.7)$ & 0 & $2(1.4)$ \\
\hline Arthralgia & $1(1.4)$ & $5(6.8)$ & $6(4.1)$ & 0 & 0 & 0 \\
\hline Paresthesia & $1(1.4)$ & $5(6.8)$ & $6(4.1)$ & 0 & 0 & 0 \\
\hline Esophageal reflux & $1(1.4)$ & $5(6.8)$ & $6(4.1)$ & 0 & 0 & 0 \\
\hline Pruritus & $2(2.7)$ & $4(5.4)$ & $6(4.1)$ & 0 & 0 & 0 \\
\hline Pain (in an extremity) & $4(5.5)$ & $1(1.4)$ & $5(3.4)$ & 0 & 0 & 0 \\
\hline Blurred vision & $4(5.5)$ & $1(1.4)$ & $5(3.4)$ & 0 & 0 & 0 \\
\hline Photosensitivity & 0 & $4(5.4)$ & $4(2.7)$ & 0 & 0 & 0 \\
\hline
\end{tabular}

*Data are for the types of events that occurred in at least 5 percent of the patients in at least one of the two groups. GI denotes gastrointestinal.

with very rapid decreases in tumor volume. Serious adverse events (grade 3 or 4 ) occurred in 21.1 percent of patients. The most serious adverse events were gastrointestinal or intraabdominal hemorrhages in patients with large, bulky tumors, which occurred in approximately 5 percent of patients.

\section{Histopathological Changes}

A subgroup of biopsies performed after treatment showed reduced numbers of tumor cells and a hypocellular myxohyaline stroma with small numbers of scattered atypical nuclei and, frequently, prominent stromal hemorrhage. Frank necrosis of the tumor was rarely seen (Fig. 3). Other biopsies showed large numbers of residual CD117-positive tumor cells, even in patients whose tumors showed a substantial reduction in size on PET and CT scanning. These residual gastrointestinal stromal tumor cells often showed pyknotic nuclei and reduced cytoplasmic volume, similar in appearance to "crush artifact."

\section{DISCUSSION}

There is compelling evidence from preclinical models that the constitutively activated KIT-receptor ty- 
A
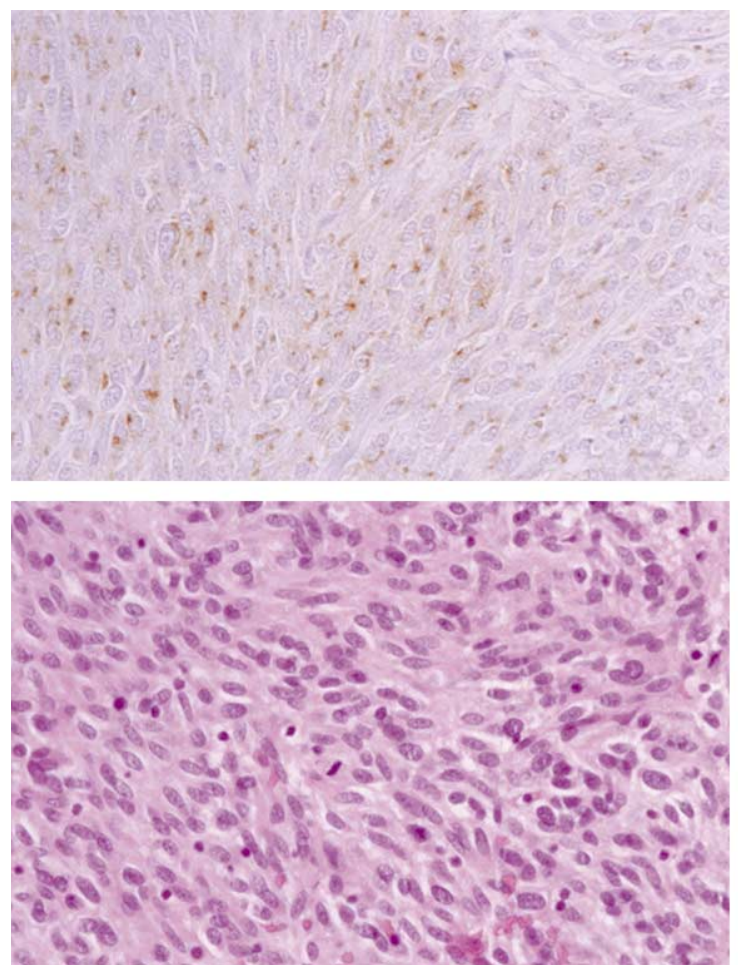

B
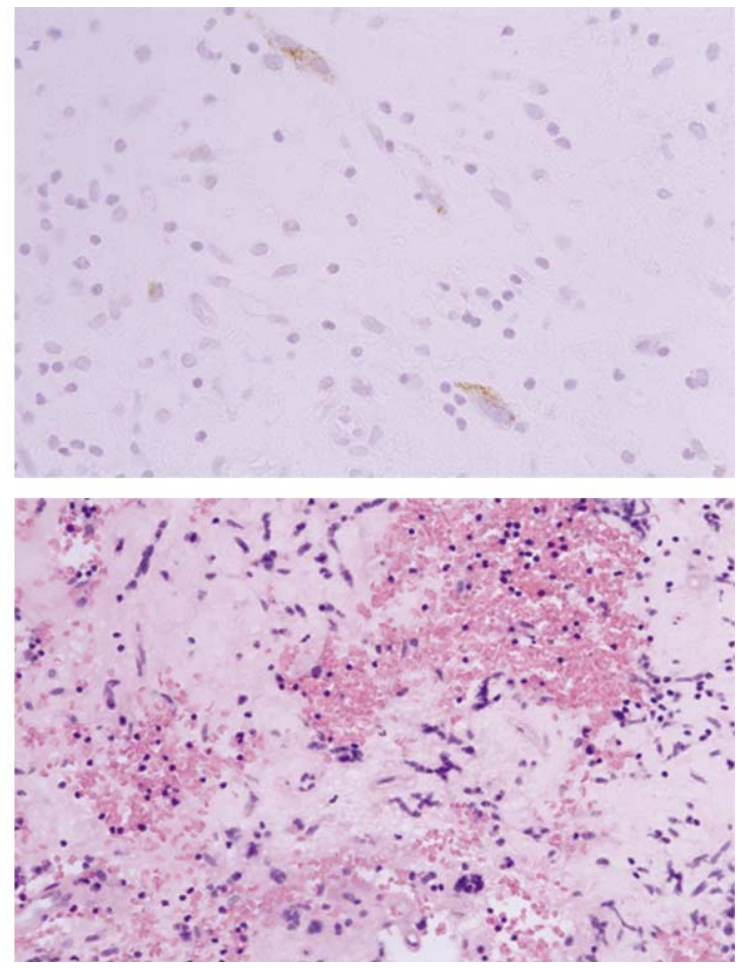

Figure 3. Biopsy Specimens of Metastatic Malignant Gastrointestinal Stromal Tumors before Treatment and after Four Weeks of Daily Treatment with Imatinib.

At base line, the CD117 immunostaining shows a dot-like pattern (top image, Panel A). Only rare CD117-positive cells are noted on immunostaining in the specimen obtained after treatment (top image, Panel B). Scattered atypical nuclei and inflammatory cells present in a myxohyaline stroma are visible on the specimen that was obtained after treatment and stained with hematoxylin and eosin (bottom image, Panel B). (The bottom image in Panel A shows hematoxylin and eosin staining of the tumor before treatment.)

rosine kinase stimulates the proliferation and enhances the survival of neoplastic gastrointestinal stromal tumor cells. In both preclinical experiments ${ }^{13}$ and a previous case study, ${ }^{14}$ inhibition by imatinib had considerable antiproliferative and proapoptotic effects on gastrointestinal stromal tumor cells. Our study demonstrates, in a large series of patients with advanced gastrointestinal stromal tumors, that imatinib is effective in most patients.

Advanced gastrointestinal stromal tumors are unresponsive to conventional chemotherapy..$^{5,6}$ The high rate of response to imatinib in these patients with bulky disease who had no response to cytotoxic chemotherapy is not only remarkable, but also supports the hypothesis that dysregulated KIT kinase activity is important in human gastrointestinal stromal tumors. Responses, although partial, have lasted for many months, as patients continue to receive daily treatment in our ongoing clinical trial. Our results corroborate the result obtained with imatinib in a single patient with a gastrointestinal stromal tumor, who is still receiving therapy more than 22 months after its initiation (unpublished data), ${ }^{14}$ and the confirmed partial responses in 19 patients in a phase 1 study of imatinib in gastrointestinal stromal tumors. ${ }^{21}$ Historical data show a median survival of 19 months for all patients with metastatic disease and 9 months for patients with metastatic disease and local recurrence. ${ }^{5}$ Despite the extensive metastatic disease in the majority of our patients, 88 percent were alive one year after the initiation of treatment with imatinib, with the median duration of survival not yet reached.

This phase 2 trial was not adequately powered to distinguish between the efficacy of the 400-mg and 600-mg doses. Although there was no statistically significant difference between the dose levels, three of the nine patients who received the higher dose after evidence of disease progression was uncovered had a sustained partial response or stable disease after the crossover. The optimally effective dose of imatinib in 
patients with a gastrointestinal stromal tumor is the subject of large, appropriately powered, randomized studies that are now under way.

The high bioavailability of orally administered imatinib in our study was generally similar to that reported in patients with chronic myeloid leukemia. ${ }^{11}$ Therapeutic plasma concentrations were attained despite the presence of altered gastrointestinal anatomy from previous, and often extensive, resections.

Overall, imatinib was well tolerated, with adverse effects similar to those reported in a large population of patients with chronic myeloid leukemia.11,12 $\mathrm{My}-$ elotoxicity was less frequent in patients with gastrointestinal stromal tumors, suggesting that the myelosuppression associated with imatinib in hematologic cancers may be related to the pathophysiology of the leukemic bone marrow. An important finding was serious gastrointestinal and tumor hemorrhage in about 5 percent of our patients. These hemorrhages could be related to the underlying disease, but they were probably related to tumor degeneration induced by imatinib.

The close relation between clinical outcome and the findings on $\left.{ }^{18} \mathrm{~F}\right]$ fluoro-2-deoxy-D-glucose PET scanning indicates that such scanning is a useful complement to standard anatomical imaging with CT or MRI for monitoring the therapeutic effect of imatinib in patients with gastrointestinal stromal tumors. The molecular mechanisms responsible for the rapid decreases in glycolytic activity associated with imatinib treatment remain unknown, particularly given that some biopsies demonstrated the continued presence of substantial numbers of viable CD117-bearing cells.

Although our results indicate that imatinib is effective for many patients with advanced gastrointestinal stromal tumors, resistance of tumors to single-agent therapy is common. In 5 percent of our patients, the tumor exhibited primary resistance to imatinib within the first two months. In other patients with disease progression, resistance became evident only after several months of treatment. Nonetheless, patients with an objective response and the majority of patients with stable disease had durable evidence of a treatment benefit lasting more than six months. These findings contrast somewhat with the experience in patients with advanced chronic myeloid leukemia. In patients treated for blast crisis, most cases of secondary resistance appeared within four months after the initial response. ${ }^{12}$ Resistance in patients with chronic myeloid leukemia is caused by more than one molecular mechanism, including amplification of the gene encoding the aberrant kinase and mutation of the drug-binding site in the kinase domain. ${ }^{22,23}$ Molecular mechanisms responsible for resistance in patients with gastrointestinal stromal tumors may be quite different. Constitutive activation of KIT receptor tyrosine kinase in gastrointestinal stromal tumors can be caused by mutations in any of several exons, and in a subgroup of patients there is no detectable KIT mutation. ${ }^{4}$ Even at the most common site of mutations (exon 11), a wide variety of in-frame deletions and substitutions has been reported. ${ }^{24}$ Careful study of molecular mechanisms will be needed in order to develop rational strategies for preventing or overcoming the emergence of resistance to imatinib in patients with gastrointestinal stromal tumors.

Supported in part by grants from Novartis Oncology, grants from the Katz Foundation, the Rubenstein Foundation, and the Quick Family (to Dr. Demetri), and grants from the Veterans Affairs Merit Review Program and Northwest Health Foundation (to Dr. Heinrich).

Drs. Demetri, von Mehren, Blanke, Van den Abbeele, Eisenberg, Heinrich, J. Fletcher, Druker, Corless, C. Fletcher, and Joensuu have consulted for or received research grants from Novartis. Drs. Silberman, Capdeville, Kiese, Peng, and Dimitrijevic are employees of and hold equity in Novartis.

We are indebted to the following persons for their contributions to the study: Suzanne George, M.D., Jeffrey Morgan, M.D., David P. Ryan, M.D., Priscilla Merriam, Amy Potter, M. Travis Quigley, R.N., B.S.N., Margaret Buonanno, Adriana Torre, Ellen Bosnak, Tricia Spangler, C.N.M.T., Richard J. Tetrault, C.N.M.T., Ramsey D. Badawi, Ph.D., Joan Canniff, R.N., Jean-Pierre Cliche, M.D., David A. Israel, M.D., Jeanne Griffin, R.N., David Harmon, M.D., Athena Moutsiolis, Judith Manola, M.Sc., Dana-Farber Cancer Institute and Harvard Cancer Center, Boston; Monica Davey, R.N., B.S.N., Barton N. Milestone, M.D., Rosaleen Parsons, M.D., Fox Chase Cancer Center, Philadelphia; Diana J. Griffith, Andrea Haley, Laura McGreevey, Lea Herndon Smith, C.C.R.P., Cecily L. Wait, Lora Wilson, R.N., B.S.N., Oregon Health and Science University, Portland; and Inkeri Elomaa, M.D., Carl Blomqvist, M.D., Pekka Virkkunen, M.D., University of Helsinki, Helsinki, Finland.

\section{REFERENCES}

1. Miettinen M, Sarlomo-Rikala M, Lasota J. Gastrointestinal stromal tumors: recent advances in understanding of their biology. Hum Pathol 1999;30:1213-20.

2. Rubin BP, Fletcher JA, Fletcher CDM. Molecular insights into the histogenesis and pathogenesis of gastrointestinal stromal tumors. Int J Surg Pathol 2000;8:5-10.

3. Lux M, Rubin BP, Biase TL, et al. KIT extracellular and kinase domain mutations in gastrointestinal stromal tumors. Am J Pathol 2000;156:791-5. 4. Rubin BP, Singer S, Tsao C, et al. KIT activation is a ubiquitous feature of gastrointestinal stromal tumors. Cancer Res 2001;61:8118-21.

5. DeMatteo RP, Lewis JJ, Leung D, Mudan SS, Woodruff JM, Brennan MF. Two hundred gastrointestinal stromal tumors: recurrence patterns and prognostic factors for survival. Ann Surg 2000;231:51-8.

6. Goss GA, Merriam P, Manola J, Singer S, Fletcher CD, Demetri GD. Clinical and pathological characteristics of gastrointestinal stromal tumors (GIST). Prog Proc Am Soc Clin Oncol 2000;19:599a. abstract.

7. Druker BJ, Tamura S, Buchdunger E, et al. Effects of a selective inhibitor of the Abl tyrosine kinase on the growth of Bcr-Abl positive cells. Nat Med 1996;2:561-6.

8. Buchdunger E, Cioffi CL, Law N, et al. Abl protein-tyrosine kinase inhibitor STI57I inhibits in vitro signal transduction mediated by c-kit and platelet-derived growth factor receptors. J Pharmacol Exp Ther 2000;295: $139-45$.

9. Heinrich MC, Griffith DJ, Druker BJ, Wait CL, Oh KA, Zigler AJ. Inhibition of c-kit receptor tyrosine kinase activity by STI 571, a selective tyrosine kinase inhibitor. Blood 2000;96:925-32.

10. Wang WL, Healy ME, Sattler M, et al. Growth inhibition and modulation of kinase pathways of small cell lung cancer cell lines by the novel tyrosine kinase inhibitor STI 571. Oncogene 2000;19:3521-8.

11. Druker BJ, Talpaz M, Resta DJ, et al. Efficacy and safety of a specific inhibitor of the BCR-ABL tyrosine kinase in chronic myeloid leukemia. N Engl J Med 2001;344:1031-7. 
12. Druker BJ, Sawyers CL, Kantariian $\mathrm{H}$, et al. Activity of a specific inhibitor of the BCR-ABL tyrosine kinase in the blast crisis of chronic myeloid leukemia and acute lymphoblastic leukemia with the Philadelphia chromosome. N Engl J Med 2001;344:1038-42. [Erratum, N Engl J Med 2001;345:232.]

13. Tuveson DA, Willis NA, Jacks T, et al. STI571 inactivation of the gastrointestinal stromal tumor c-KIT oncoprotein: biological and clinical implications. Oncogene 2001;20:5054-8.

14. Joensuu H, Roberts PJ, Sarlomo-Rikala M, et al. Effect of the tyrosine kinase inhibitor STI571 in a patient with a metastatic gastrointestinal stromal tumor. N Engl J Med 2001;344:1052-6.

15. Green S, Weiss GR. Southwest Oncology Group standard response criteria, endpoint definitions and toxicity criteria. Invest New Drugs 1992; 10:239-53.

16. Cancer Therapy Evaluation Program. Common toxicity criteria man ual: common toxicity criteria, version 2.0. Bethesda, Md.: National Cance Institute, June 1999. (Also available at http://ctep.cancer.gov/forms/ CTCManual_v4_10-4-99.pdf.)

17. Hornick JL, Fletcher CDM. Immunohistochemical staining for KIT (CD117) in soft tissue sarcomas is very limited in distribution. Am J Clin Pathol 2002;117:188-93.

18. Bakhtiar R, Lohne J, Ramos L, Khemani L, Hayes M, Tse F. Highthroughput quantification of the anti-leukemia drug STI571 (Gleevec) and its main metabolite (CGP 74588) in human plasma using liquid chroma- tography-tandem mass spectrometry. J Chromatogr B Biomed Sci Appl 2002;768:325-40

19. Fletcher CD, Berman JJ, Corless C, et al. Diagnosis of gastrointestinal stromal tumors: a consensus approach. Hum Pathol 2002;33:459-65.

20. Peng $B$, Hayes $M$, Racine-Poon $A$, et al. Clinical investigation of the pharmacokinetic/pharmacodynamic relationship for Glivec (STI571): a novel inhibitor of signal transduction. Prog Proc Am Soc Clin Oncol 2001; 20:7la. abstract.

21. van Oosterom AT, Judson I, Verweij J, et al. Safety and efficacy of imatinib (STI571) in metastatic gastrointestinal tumors: a phase I study. Lancet 2001;358:1421-3.

22. le Coutre P, Tassi E, Varella-Garcia M, et al. Induction of resistance to Abelson inhibitor STI571 in human leukemic cells through gene amplification. Blood 2000;95:1758-66.

23. Gorre ME, Mohammed $M$, Ellwood $K$, et al. Clinical resistance to STI-571 cancer therapy caused by BCR-ABL gene mutation or amplification. Science 2001;293:876-80.

24. Miettinen M, Furlong M, Sarlomo-Rikala M, Burke A, Sobin LH, Lasota J. Gastrointestinal stromal tumors, intramural leiomyomas, and leiomyosarcomas in the rectum and anus: a clinicopathologic, immunohistochemical, and molecular genetic study of 144 cases. Am J Surg Pathol $2001 ; 25: 1121-33$

Copyright (C) 2002 Massachusetts Medical Society.

FULL TEXT OF ALL JOURNAL ARTICLES ON THE WORLD WIDE WEB

Access to the complete text of the Journal on the Internet is free to all subscribers. To use this Web site, subscribers should go to the Journal's home page (http://www.nejm.org) and register by entering their names and subscriber numbers as they appear on their mailing labels. After this one-time registration, subscribers can use their passwords to log on for electronic access to the entire Journal from any computer that is connected to the Internet. Features include a library of all issues since January 1993 and abstracts since January 1975, a full-text search capacity, and a personal archive for saving articles and search results of interest. All articles can be printed in a format that is virtually identical to that of the typeset pages. Beginning six months after publication the full text of all original articles and special articles is available free to nonsubscribers who have completed a brief registration.

480 • N Engl J Med, Vol. 347, No. 7 • August 15, $2002 \cdot$ www.nejm.org 